\title{
Assessment of Productivity and Profitability through Scientific Forest Management in Sal (Shorea robusta) Forest of Nepal: A Case Study from Patela Community Forest, Kailali District, Nepal
}

\author{
Pabitra Gotame ${ }^{1}$, Yam Bahadur K.C..$^{*}$ and Nripesh Awasthi ${ }^{2}$
}

\begin{abstract}
Scientific forest management (SciFM) ensures improved productivity and healthy forests that are crucial for the economic development and prosperity of forest-dependent country like Nepal. This study analyzes the effects of the silvicultural intervention on the regeneration of Sal (Shorea robusta), plant species diversity, and income through the flow of forest products in the Patela Community Forest in Kailali District of Nepal, where Sal (S. robusta) forest has been managed under an Irregular Shelterwood System with 80 years of the rotation period since fiscal year $2017 / 18$. The vegetation sampling was done by the quadrat method based on the principle of stratified random sampling from the managed and unmanaged parts of the forest. The climate based site productivity was analyzed. The profitability of scientific forest management was analyzed by income and cost incurred in managing the forest. The study revealed the promising regeneration of $S$. robusta in the managed areas compared to the unmanaged area. The silvicultural intervention had a significant negative effect on plant diversity showing an increase in the concentration of dominance of S. robusta. An implementation of SciFM plan generated a total net benefit of 187,000 US\$ in the last 2017/18, and 2018/19 fiscal years. This study recommends existing natural forests to be managed based on sound silvicultural principles to improve the degrading nature of the productive forest that can generate revenue for the country and opportunity for community development.
\end{abstract}

Key words: Community forest, regeneration, plant diversity, income, silvicultural intervention

Gotame, P., Y.B. K.C., and N. Awasthi. 2020. Assessment of Productivity and Profitability through Scientific Forest Management in Sal (Shorea robusta) Forest of Nepal: A Case Study from Patela Community Forest, Kailali District, Nepal. No. 17: page 23 to 41. DOI: https://doi.org/10.3126/forestry.v17i0.33620

\footnotetext{
1 Tribhuvan University, Institute of Forestry, Hetauda Campus, Nepal

2 Ministry of Industry, Tourism, Forests and Environment, Sudoorpaschim province, Nepal

* Corresponding author.email:ykc@iofhc.edu.np
} 


\section{Introduction}

The concept of Scientific Forest Management (SciFM) is not new, as it dates back to the late eighteenth century in Germany, which has later been adopted by several training institutions and forest bureaucracies throughout the world (Rutt et al. 2015; Khanal and Adhikari 2018). In Nepal, SciFM approach was first introduced to the lowland Terai region in 2010. The essentiality of SciFM is the statistically sound forest inventories that determine the growing stocks as well as annual increment with sufficient accuracy to ensure that harvesting does not exceed the re-growth over longer-term while maintaining environmental services, such as erosion control, watershed protection, wind protection, species habitat and carbon storage (Rutt et al. 2015). The original scope of SciFM in sustainable timber production and meeting economic objectives has since then widened to include social, cultural, and environmental aspects (FAO 2016).

The government of Nepal has been making efforts to manage the forest of lowlands of Nepal scientifically for economic growth of the nation as well as for benefit of local people. For example, the government initiated managing productive forest of Terai by preparing Operational Forest Management Plan (OFMPs) in the 1990s; similarly, SciFM guidelines were developed in 2014 and endorsed for the promotion of silviculture based sustainable forest management in Forest Policy (2015 and 2019) and also in $15^{\text {th }}$ Five-year National Periodic Plan (2019/20-2023/24) for proper implementation of SciFM, especially focusing on Sal and Mixed hardwood forests under the collaborative and community forest management systems of the Terai and Mid-hills regions of Nepal. The government has clearly defined SciFM as an application of appropriate silviculture systems and forest management principles through the design of systematic compartments of fixed rotation age. This follows primarily the Irregular Shelterwood Silvicultural System with very high-intensity logging, leaving behind 15-30 mature mother trees per hectare (DoF 2014). The vision of the government outlined as "Forestry for Prosperity" laid the policy foundation for SciFM as one of the four key pillars of prosperity (Poudel 2018; Poudyal et al. 2019).

Nepal has experienced a tremendous loss of foregone benefits from the forest as a result of protection oriented forest management neglecting scientific and silviculture based active forest management (Subedi 2011; Banjade et al. 2012; Poudel 2018). For example, the country is losing annual revenue ranging from 19.12 to 38.62 billion rupees; attributed to the protection oriented management, low production, and hence unsustainable management of forest (Subedi 2011; MFSC 2016). Similarly, the steady decline of the Terai forest during 2001-2010 and 1991-2010, with $0.44 \%$ and $0.40 \%$ loss per year, respectively, indicates that forest management practices are not sustainable (DFRS 2015). Besides, the demand and supply of timber resources are not still well-balanced in the context of Nepal, stimulating for illegal logging and timber smuggling (Subedi 2011; NFA 2012). As such, the utmost need for scientific and silvicultural intervention at the policy and field-level was realized to promote regeneration in the old-growth forest and ensure replacement of old stock with a 
new one in the future ensuring good future productivity and profitability. SciFM is an emerging and popular approach of Nepal for managing existing productive forests based on silvicultural intervention, as it follows a silvicultural system and helps in maintaining better forest health and vitality as well as improving the sustainable flow of forest products, environmental services, and revenues for the nation (Awasthi et al. 2015; Khanal and Adhikari 2018; Awasthi et al. 2020).

The regeneration status indicates the health and vitality of the forest and a healthy forest ensures good future regeneration (Awasthi et al. 2015). Moreover, the natural regeneration of $S$. robusta is complex and faces baffling problems (Chauhan et al. 2008), mostly arising due to by climate (light intensity), soil (moisture), seeds, and biotic factors (Singh et al. 1987; Tyagi et al. 2011) and the Sal forest is degrading day by day because of their economic significance (Sapkota et al. 2009). Maintaining the productive capacity and biological diversity of any forest area is an important criterion for sustainable forest management that can be predicted by measuring and analyzing the regeneration (Lutze et al. 2004). The productive character and dynamics of the forest are determined by the presence of different age-group and diversity in seedling, sapling, and tree (Chauhan et al. 2008; Awasthi et al. 2020). The forest regeneration will guarantee its future to produce wood and other forest service continuously; we need permanence in productivity of the forest. To be silviculturally sustainable, forest management must ensure good regeneration; maintain proper age classes or age gradation, and normal growing stock and hence normal increment (Subedi 2011).

Forest area covers $44.74 \%$ of the total area of Nepal, almost half of the land area (FRA/DFRS 2014). Scientific management and proper utilization of these resources are the utmost and prominent for the economic development of the country. But, in reality, the protection oriented forest management in Nepal is unable to address the timber and fuelwood demand, which results in illegal felling and smuggling of wood, which in turn has been driving degradation and loss of forest resources. Since SciFM in Nepal aims to promote productive species (viz. Sal in Terai and Pinus in hills) for meeting high timber demand and incorporates harvesting of those species as part of the silvicultural intervention, the study against these harvesting interventions is significant and crucial for further replicating the program based on income-cost incurred, quality and quantity of timber and firewood, employment generated and ensuring benefits for future generations by establishing sound forest condition. Various studies on Sal attempted to focus mainly on regeneration status and biodiversity. This study aims to analyze the potential and growth performance of the early establishment of regeneration as well as revenue generated against established silvicultural intervention in the Sal forest of the country. Therefore, this study intends to assess the effectiveness of silvicultural operation as adopted by the government of Nepal, especially with regard to the regeneration of highly valuable Sal forest and maintaining biodiversity as well as optimization of forest income through the flow of forest resources in the forest management scenario of Nepal. 


\section{Materials and Methods}

\section{Study Area}

The study was carried out in the Patela Community Forest (CF), located in the Dhangadhi sub-metropolitan city of Kailali district, Sudurpaschim province, Nepal (Figure 1). Kailali district extends from $28^{\circ} 22^{\prime} \mathrm{N}$ to $29^{\circ} 05^{\prime} \mathrm{N}$ latitude and 80 $0^{\circ} 0^{\prime} \mathrm{E}$ to $80^{\circ} 18^{\prime}$ E longitude, covering an area of $3235 \mathrm{~km}^{2}$, of which $40 \%$ falls within the plain Terai and the rest in the Chure hill range. The climate of the district varies from tropical to sub-tropical with altitude ranging from $109 \mathrm{~m}$ to $1950 \mathrm{~m}$ from the mean sea level. The average temperature ranges from $5^{\circ} \mathrm{C}$ in winter to $43^{\circ} \mathrm{C}$ in autumn with an average annual precipitation of $1840 \mathrm{~mm}$ (DDC 2015). The total area of CF is 207.05 ha dominated by Sal (S. robusta). Other species include Asna (Terminalia tomentosa), Banjhi (Anogeissus latifolia), Karma (Adina cordifolia), and Jamun (Syzygiumcumini). It was handed over to 98 households with 585 people for management in 2009, while SciFM in this CF was implemented from the fiscal year 2017/18. The forest has been managed under an Irregular Shelterwood System, a well prescribed silvicultural system by SciFM guideline, 2014. Irregular shelterwood system is a trade-off between the Shelterwood Group System and the group selection system (Parkash and Khanna 1979). The whole forest area has been divided into 8 periodic blocks (C1SCs) for the management of Sal forest with a 10-years regeneration period and an 80-years rotation period. The area control method of yield regulation has been followed. Hence, each periodic block has been sub-divided into 10 annual sub-blocks of equal area (2.14 ha), where regeneration felling activities are carried out each year (PCFMOP 2017).

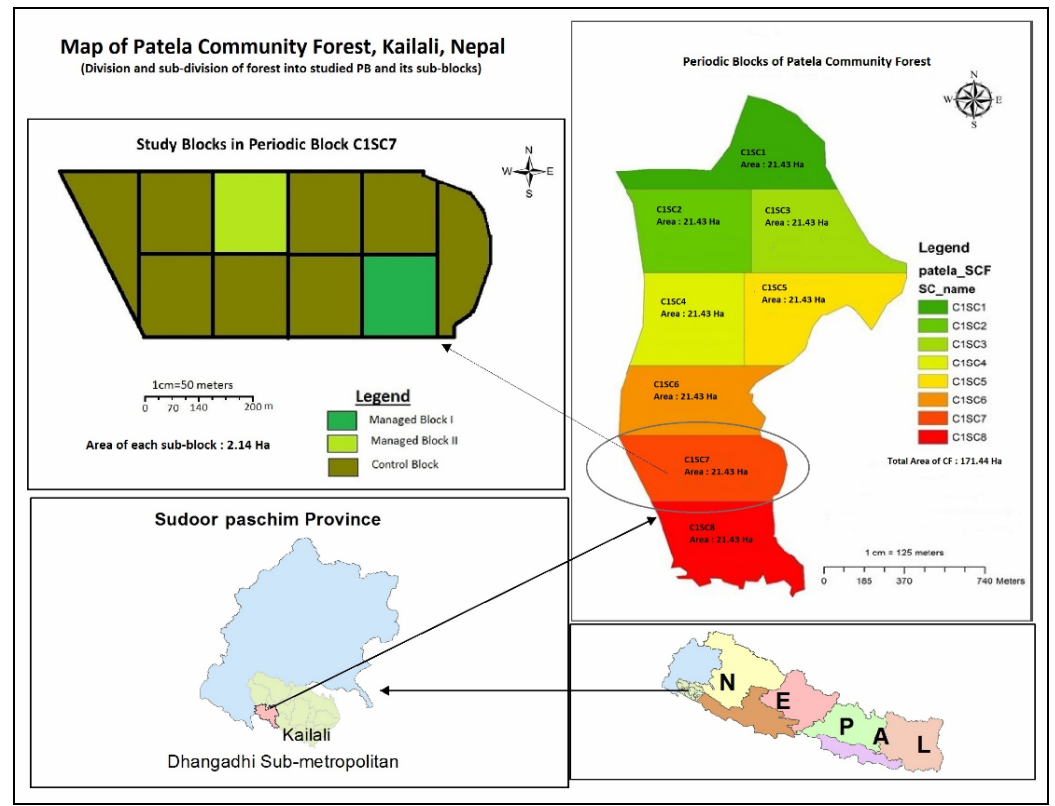

Figure 1: Location map of the study area 
The two annual sub-blocks out of 10 in periodic block, C1SC7 were managed through regeneration felling and post-harvest operation until the data collection time of this study. The annual sub-blocks (hereafter "managed block I", first-year stand; "managed block II", second-year stand) were selected as managed blocks (regulated/ regeneration felling), while the other 8 annual sub-blocks, within the periodic block, C1SC7, where there was no intervention made, were considered as an unmanaged block (hereafter "control block"). All the annual sub-blocks have an equal area of 2.14 ha, thus, the areas of the managed block I and II were 2.14 ha each, whereas the area of unmanaged blocks (with 8 annual sub-blocks) was 17.12 ha (PCFMOP 2017).

\section{Data Collection}

\section{Biophysical Data}

The quadrat method was used for vegetative samplings following Mishra (1968) and Basyal et al. (2011). Individual tree species were divided into three growth stages as a tree $(\mathrm{dbh}>10 \mathrm{~cm})$, sapling $(\mathrm{dbh}<10 \mathrm{~cm}$; height $>1.3 \mathrm{~m})$, and seedling (height $<1.3 \mathrm{~m}$ ). The quadrants of $10 \mathrm{~m} \times 10 \mathrm{~m}$ were laid out in the study area for trees based on stratified random sampling techniques with the help of ArcGIS 10 and each quadrate was divided into four equal ( $5 \mathrm{~m} \times 5 \mathrm{~m}$ size) sub-quadrates from the center and two opposite sub-quadrates used for studying saplings and seedlings, as determined by species-area curve method (Mishra 1968). The height and dbh of tree and sapling were measured using Abney's level and Diameter tape, and crown cover (\%) with a densiometer in each sampling unit. Data were collected from September to October in 2019. As the size of managed and control blocks vary, altogether, 10 and 30 sample quadrates were studied from two managed and, control blocks respectively with $2.33 \%$ sampling intensity for each managed block $(2.14 \mathrm{ha})$ and $1.75 \%$ for the unmanaged block (17.12 ha), based on the nature of the forest and the objective of the study. In addition, meteorological data (temperature and precipitation) were collected for calculating the CVP index of the site from the Department of Hydrology and Meteorology (DHM 2017), Nepal.

\section{Socio-Economic Data}

The flow of forest products, income, and expenditure trends were collected from annual and audit reports of CFUG. Collected data were also triangulated through discussions with committee members, and office staff of the CFUG and Division Forest Office, Kailali.

\section{Data Analysis}

The plant community composition both in the managed and unmanaged blocks was calculated by Importance Value Index (\%) determining density (Individual per hectare, Ind/ha), basal area $\left(\mathrm{m}^{2}\right)$, and frequency (\%) for each species, adopted by Mueller-Dombois and Ellenberg (1974). Similarly, plant diversity in the managed and unmanaged blocks was calculated using Shannon Wiener's Index, Simpson's Dominance Index, Margalef's Species Richness Index, Equitability or Evenness 
Index, and Jaccard's Similarity Index which exclude herbs or climber layers. These indices were calculated using:

Importance Value Index (IVI) = Relative Frequency + Relative Basal Area + Relative Density,

Shannon Wiener's Index $\left(\mathrm{H}^{\prime}\right)=-\sum_{\mathrm{i}=1}^{\mathrm{S}}(\mathrm{pi})(\mathrm{In} \mathrm{Pi})$,

Simpson's index of dominance $(C)=\sum_{\mathrm{i}=1}^{\mathrm{S}}(\mathrm{pi})^{2}$,

Margalef's Species Richness Index $(S)=\frac{(\mathrm{s}-1)}{\mathrm{InN}}$,

Equitability or Evenness Index $(E)=\frac{\mathrm{H}^{\prime}}{\mathrm{Ins}} \quad$, and

Jaccard's Similarity Index, JI $=\frac{c}{a+b+c}$

where, $\mathrm{s}$ is number of species, $\mathrm{N}$ is total number of individuals of species, $\mathrm{pi}$ is proportion of all individuals that are of species ' $i$ ', c is common species in two community, $a=$ species only found in one community and $b$ is species only found in another community.

The ratio of abundance to frequency distribution was considered regular if it was less than 0.025 , random if it was within $0.025-0.05$, and contagious if it was over 0.05 (Whitford 1949). Moreover, the potential productivity of the study site was calculated by the productivity function given by Paterson's CVP index (Paterson 1956):

CVP index $=\frac{\operatorname{Tv} \times P \times G \times E}{\operatorname{Ta} \times 12 \times 100}$

where, $\mathrm{Tv}$ is the mean maximum temperature $\left({ }^{\circ} \mathrm{C}\right)$,

Ta is difference between mean maximum and mean minimum temperature $\left({ }^{\circ} \mathrm{C}\right)$,

$\mathrm{P}$ is the mean annual precipitation $(\mathrm{mm})$,

$\mathrm{G}$ is growing season in months,

$E$ is the evapotranspiration intensity based on location (i.e. latitude).

Data were analyzed by descriptive (mean, frequency, standard error) as well as inferential statistics (One way ANOVA, post-hoc LSD, Pearson's correlation) through SPSS software. 


\section{Results and Discussion}

\section{Results}

\section{Species Composition and Distribution Pattern}

The total numbers of plant species recorded were 10 and 13 in the managed blocks (I and II, respectively) and 23 in the control block. The S. robusta was found to be the dominant species with IVI values of 205.76, 128.67 in managed blocks, and 155.83 in control block, while Asna (Terminalia tomentosa) was found to be co-dominant species with IVI values of 23,80 , and 38 , respectively in all managed blocks and control block. The dominance and distribution pattern of tree species in managed blocks I and II and the control block is shown in Figure 2. The numbers of plant species exhibiting contagious distribution in managed blocks I and II, and control block were 8,5 , and 18 respectively. The ratio of abundance to the frequency of tree species that was greater than 0.05 showed a clumped (contagious) pattern of species distribution, observed comparatively lower in all species of managed block II.
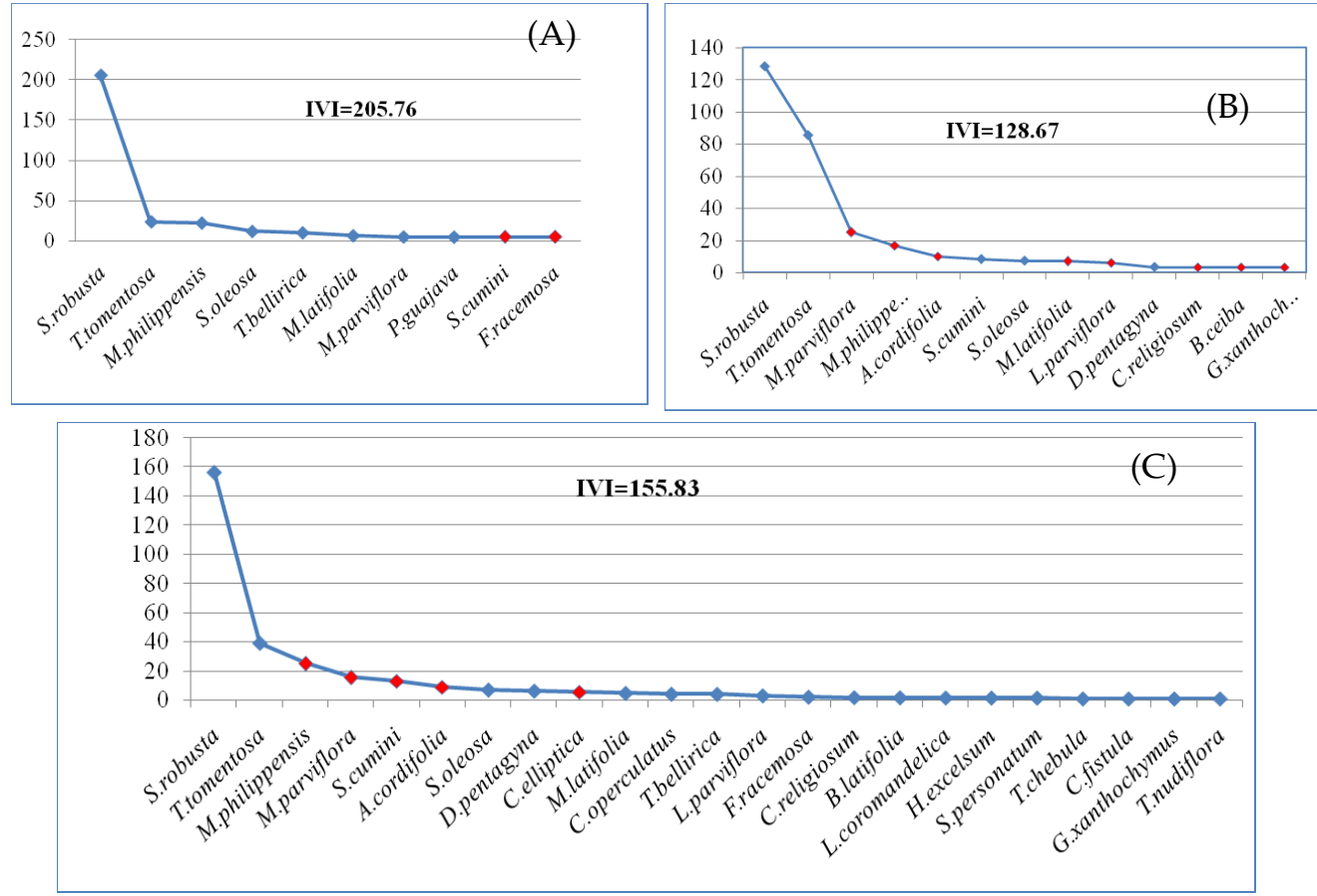

Figure 2: Dominance diversity curve in (A) Managed block I; (B) Managed block II; and (C) Control block (Blue and red dots represent contagious and randomly distributed species respectively) 


\section{Plant Species Diversity}

\section{Species Richness, Diversity, Evenness and Dominance}

The species diversity, concentration of dominance, evenness, and richness index in studied blocks are shown in Table 1. There is low mean Shannon Weiner's Index in the managed block as compared to that in the control block of the forest. Species diversity is generally found inversely related to the concentration of dominance/Simpson's dominance index. Thus, the mean value of the concentration of the dominance of managed blocks I and II was found higher (0.66 and 0.58, respectively) than the control block (0.39) due to lower diversity within the species, and depicting $S$. robusta dominating species in the managed stands. Based on oneway ANOVA, the mean value of the Shannon-Weiner index, Simpson's concentration of dominance index, evenness index, and Margalef's species richness index varies significantly $(\mathrm{p}<0.10)$ between managed and control blocks. Similarly, post hoc analysis showed that the mean value of Shannon-Weiner diversity, the concentration of dominance, and evenness indices vary significantly $(p<0.05)$ between managed block I and control block as well as managed block II with control block (Table 1). The difference in mean species richness index from the control block was found to be significantly different from that of managed block I ( $p$-value $<0.05$ ) but only marginally different from that of the managed block II $(\mathrm{p}<0.10)$.

Table 1: Mean and standard errors of species diversity indices

\begin{tabular}{lllll}
\hline Block & $\left(\mathbf{H}^{\prime}\right)$ & $(\mathbf{C})$ & $(\mathbf{E})$ & (S) \\
\hline Managed block I & $0.66 \pm 0.06$ & $0.66 \pm 0.04$ & $0.49 \pm 0.07$ & $0.77 \pm 0.13$ \\
Managed block II & $0.88 \pm 0.19$ & $0.58 \pm 0.09$ & $0.47 \pm 0.09$ & $1.18 \pm 0.14$ \\
Control block & $1.24 \pm 0.05$ & $0.39 \pm 0.02$ & $0.71 \pm 0.03$ & $1.57 \pm 0.08$ \\
\hline
\end{tabular}

Note: $H^{\prime}$ is the Shannon Wiener's Index; C: Simpson's Dominance Index/Concentration of Dominance; E: Evenness Index and S: Species Richness Index

The Jaccard's Similarity Index showed a high similarity in the species between managed block II and control block (unmanaged) block of the study area (Table 2). There was a high dissimilarity between managed block I with the control block that may be due to the post-harvesting of unwanted species in the course of weeding and cleaning.

Table 2: Jaccard's Similarity Index

\begin{tabular}{ll}
\hline Area of interest & Jaccard's Index (\%) \\
\hline Managed block I with managed block II & 43.75 \\
Managed block I with control block & 37.50 \\
Managed block II with control block & 50.00 \\
\hline
\end{tabular}




\section{Regeneration status}

\section{Forest Condition}

Overall, the seedling density (17240 Ind/ha) and sapling density (2280 Ind/ha) were found to be highest in the managed block II, as shown in Figure 3. The control block showed the least seedling density (6133.33 Ind/ha) among the three blocks, as shown in Figure 3. However, the sapling density (2280 Ind/ha) in the control block was found to be higher than the block I. The tree density ( 263 Ind/ha) remained higher in the control block where regeneration felling was not conducted.

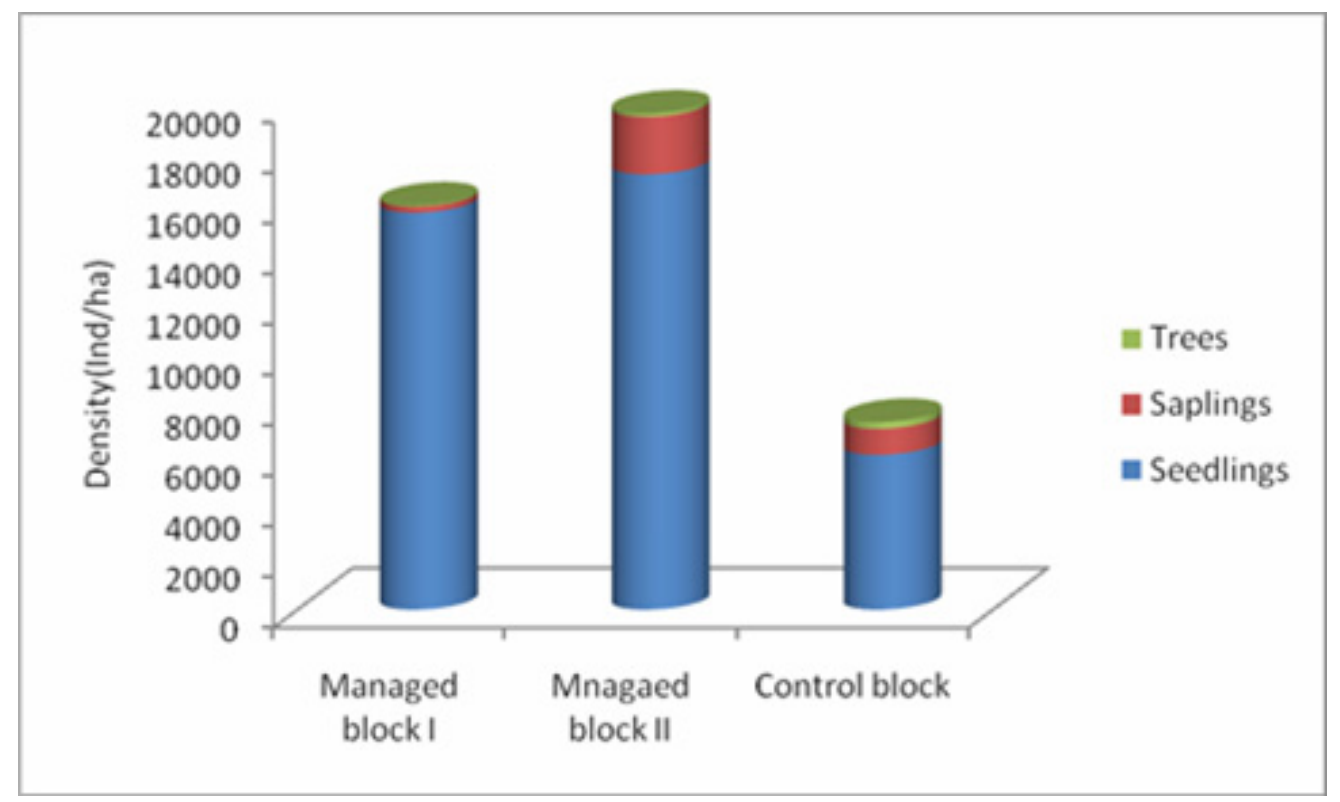

Figure 3: Seedling, sapling and tree density in the forest

\section{Regeneration of S. robusta in contrast to other species}

The seedling density of $S$. robusta was found to be higher in the managed area (Block II with 13680 Ind/ ha and Block I with 12840 Ind/ha) and lower (4100 Ind/ ha) in the control block (Figure 4). Similarly, the sapling density was also found to be higher in the managed area (Block II with 800 Ind/ha and Block I with 200 Ind/ha) and lower (127 Ind/ha) in the control block. In contrast to the other species, the seedling density of S. robusta was found to be relatively higher in the managed Block II followed by Block I and the lowest in the control block. 


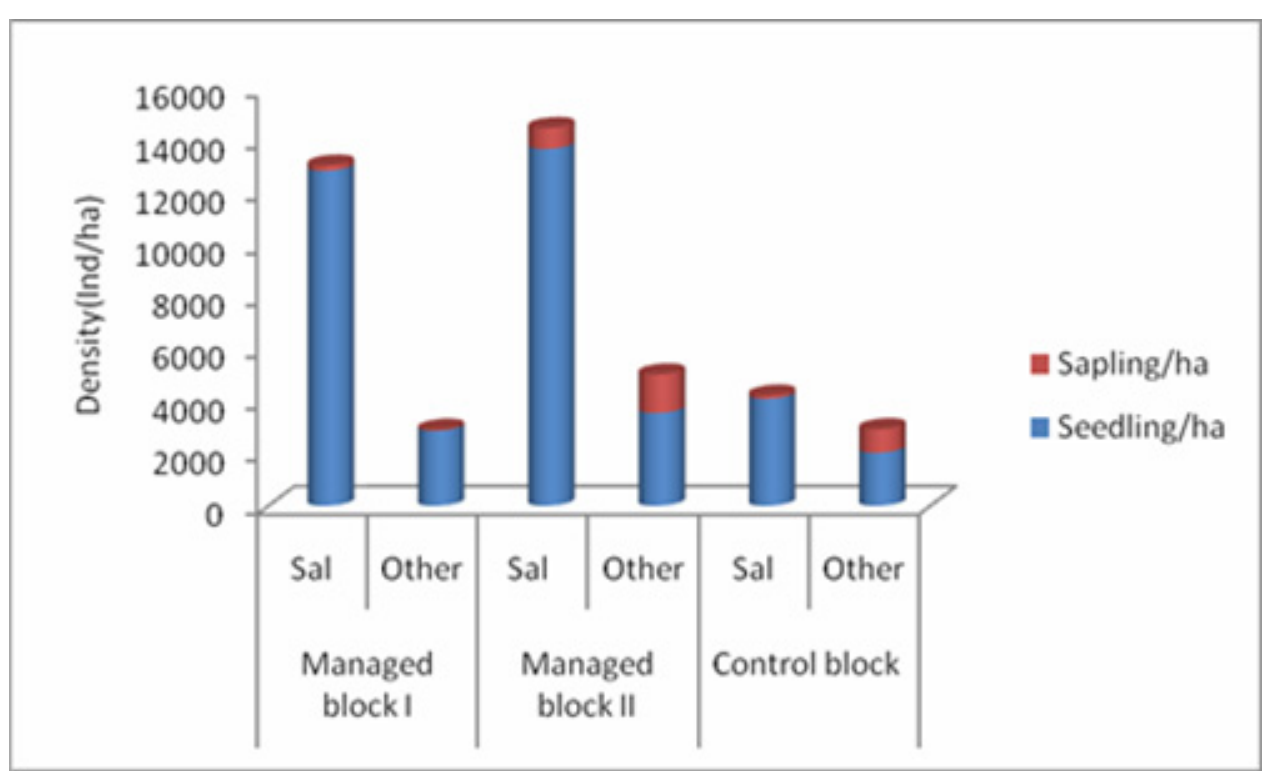

Figure 4: Regeneration comparison of $S$. robusta with other species

\section{Relationship of Regeneration/Diversity of the Forest with Crown Cover}

The total seedling and specific Sal seedling density were found to be strongly negatively correlated with the canopy cover while total sapling, as well as sapling density of Sal, remain statistically not significant (Table 3), representing the role and significance of canopy opening in developing environments for seedlings rather than that of saplings. Similarly, the value of Shannon Weiner's index and Evenness index showed a significant positive correlation with canopy cover while the concentration of Dominance index value was found significant negatively correlated with canopy cover. On the other hand, Species richness showed a positive correlation with canopy cover, though found statistically insignificant (Table 4).

Table 3: Correlation between canopy cover and regeneration of the forest

\begin{tabular}{|l|c|c|c|c|}
\hline & Seedling density & Sapling density & Sal seedling & Sal sapling \\
\hline Canopy cover & $-0.78^{* *}$ & -0.18 & $-0.762^{* *}$ & -0.211 \\
& 0.000 & 0.252 & 0.000 & 0.19 \\
\hline
\end{tabular}

Table 4: Correlation between canopy cover and species diversity of the forest

\begin{tabular}{|l|c|c|c|c|}
\hline & \multicolumn{1}{|l|}{ H' $^{\prime}$} & C & E & S \\
\hline Canopy cover & $0.50^{* *}$ & $-0.68^{* *}$ & $0.813^{* *}$ & 0.20 \\
& 0.001 & 0.000 & 0.000 & 0.21 \\
\hline
\end{tabular}

Note: $H^{\prime}$ is the Shannon Wiener's Index; C: Simpson's Dominance Index/Concentration of Dominance; E: Evenness Index and S: Species Richness Index; ${ }^{* *}$ represent significant at 0.01 level of significance (2-tailed) 


\section{Climate, Vegetation and Productivity (CVP) index}

The CVP index and the potential productivity of the study area were found to be 1112.3 and 8.60 cubic meters per hectare per year, respectively. For this analysis, climatic data were derived from 43 years of data from 1971-2014 published by DHM Nepal (DHM 2017). The average precipitation used was $1719 \mathrm{~mm}$, while the mean maximum temperature for hot weather was taken as $23.9^{\circ} \mathrm{C}, 8$ months as a growing period out of 12 , and $46 \%$ as evapotranspiration rate as determined by the location of the site based on the method prescribed by Paterson (1956).

\section{Existing and Projected Flow of Forest products from the Forest}

Based on the Community Forest Management Operation Plan, the total growing stock of the community forest and periodic block (C1SC7) was $195.48 \mathrm{~m}^{3} /$ ha and 202 $\mathrm{m}^{3} /$ ha respectively and also expected to generate timber of $17036.71 \mathrm{cft}$ and firewood of $9500 \mathrm{cft}$ annually from management operations. The major sources for the flow of timber and firewood from the forest were regeneration felling operations followed by post-harvest, cleaning, and sapling thinning and so on in an appropriate block in proper intensity as required and also from the development of firelines within the periodic block (C1SC7) and collection of dead, dying and diseased trees throughout the forest area. The production of timber (round) and firewood were $12,859.3 \mathrm{cft}$ and $18,000 \mathrm{cft}$, respectively, in the first year (FY 2017/18) and 18,718.8 cft and 25,250 cft, respectively, in the second year (FY 2018/19) (Figure 7). Among them, most of the timber and firewood were recorded to be generated from regeneration felling (41\%) and firelines development operation (41\%) followed by the collection of dead, dying, and diseased trees throughout the CF (18\%), revealing the higher production of forest products in implementing the SciFM plans in contrast to the passive management which focused only on selective felling of dead, dying and diseased trees.

The average number of trees in the managed blocks I and II were found to be $98 /$ ha and $86 /$ ha respectively. The number of felled trees per ha in the managed blocks I and II were 81 and 68 respectively generating timber of $6532 \mathrm{cft}$ and $6292 \mathrm{ctt}$ respectively, and firewood of $10500 \mathrm{cft}$ and $10000 \mathrm{ctt}$ respectively. The number of mother trees per hectare retained in the managed blocks I and II are respectively 17 and 18 for securing the quality seeds for promoting the regeneration. Similarly, the average annual projected production of timber and firewood in managing the remaining 8 annual sub-blocks through only regeneration felling would be 2232 $\mathrm{ctt} / \mathrm{ha}$ and $3500 \mathrm{cft} / \mathrm{ha}$, respectively. Besides, an average annual projected timber and firewood production in the rest of 8 years would be $5464.12 \mathrm{cft} / \mathrm{ha}$ and 7502.71 $\mathrm{cft} / \mathrm{ha}$ respectively. 


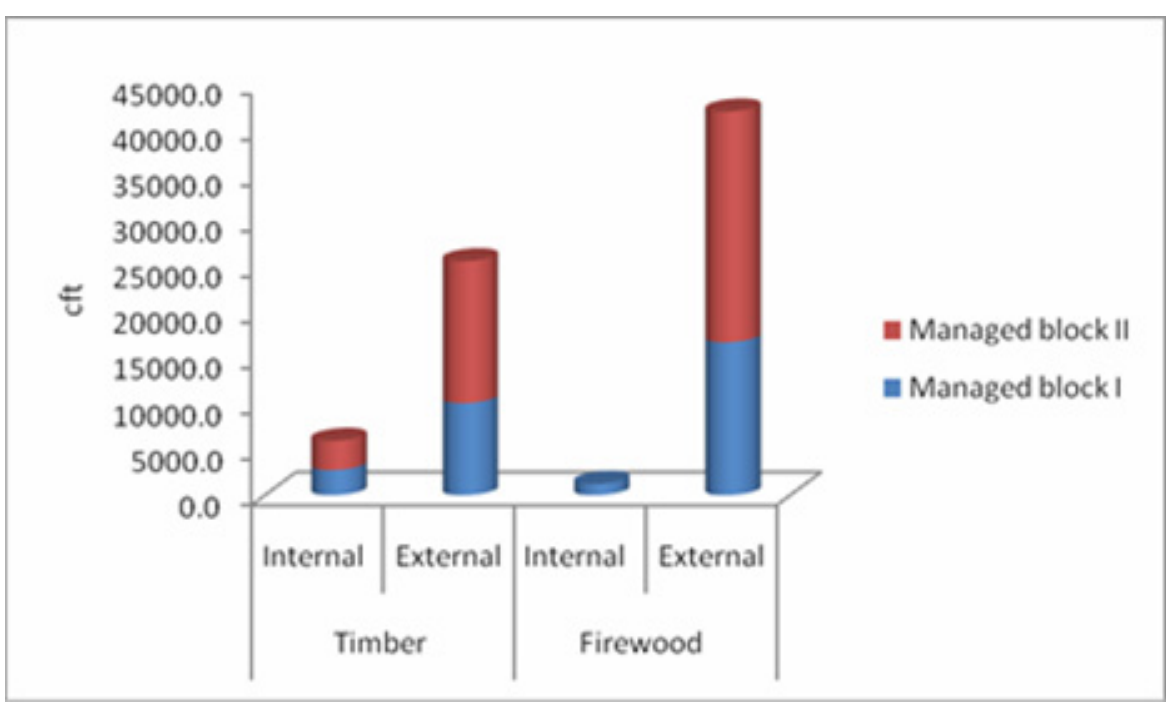

Figure 7: Consumption of forest products obtained from forest

Two consumption patterns of timber and fuelwood generated from forest were observed, i) internal within user groups and ii) external (outsourcing). In this regard, the internal consumption of the forest products (either timber or firewood) was found to be quite lower and most of them were found sold through biddings in the past two years (Figure 7).

\section{Existing and Projected Flow of Income and Expenditure from Forest}

The flow of income and expenditure incurred in managing community forest (regeneration felling, firelines creation, collection of dead, dying, diseased trees and post-harvest operation) in two fiscal years are shown in figure 8. As for determining expenditure in managing the Periodic Block I of the forest, initial cost before initiating the specific SciFM plans included cost for a boundary survey, stem mapping, fire line construction, fencing around the periodic block, and cost regarding the preparation of the plan, which was 10,973 US\$*. The costs mainly included in SciFM are forest management cost (weeding, cleaning, thinning, and plantation), maintenance cost, protection cost (patrolling/forest watcher), timber, and firewood collection/harvesting, fireline development, and plowing/ regeneration promotion activities in regeneration felled areas. The audit report of CFUG showed that the higher expense was on forest management, followed by harvesting, and administrative expenses. The total expense was 52,547 US\$ in the last two years. At the market price, the total income generated in two fiscal years from forest products was 239,924 US\$. Thus, the net total benefit generated in the last two years was approximately 187,000 US\$, while the net projected benefit generation from the forest in managing the rest of 8 years was 633,000 US\$, after deducting all

*1dollar (US \$) = 100 Nepalese Rupees 
the relevant expenditures related to management that may occur in future. The higher the net benefit generation from management (the gap between management cost and potential incomes), the more would be opportunity and alternatives for community user groups in community development and income generation activities.

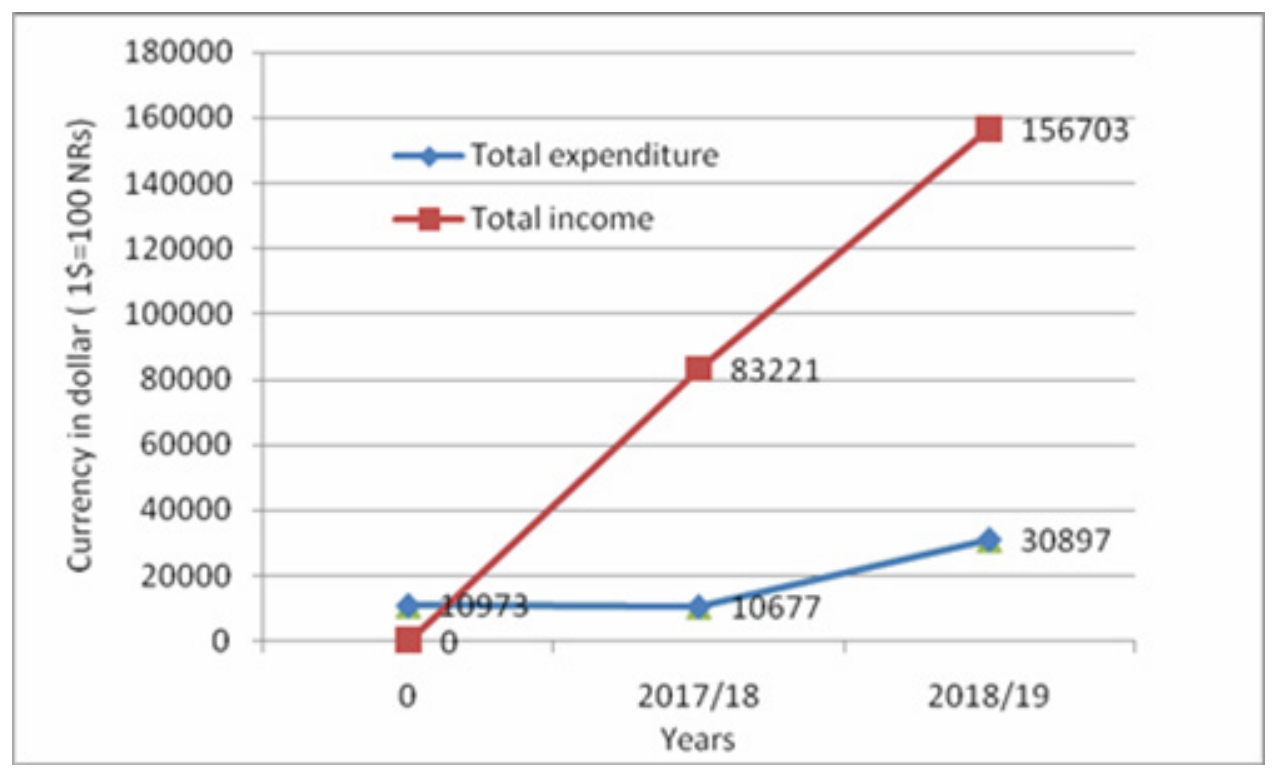

Figure 8: Flow of cost and income in managing Community forest

\section{Discussion}

The study found that implementing SciFM in community forest ensures the promising forest health in terms of sound regeneration of intended species ( $S$. robusta) and the productivity of forest through the flow of forest products (timber and firewood). This could further lead to the profitability for the community users group in regulating the forest yields under a silvicultural system.

In all the blocks, Sal (S. robusta) was found to be the dominant species followed by Asna (T. tomentosa), which is similar to the findings of the Terai forest inventory of 2010-2012 (DFRS 2015). Odum (1971) emphasized the contagious distribution patterns as the most common patterns in nature, which indicates that most seedlings were adapted to grow closer to the mother plants. The study encountered about $80 \%$, $38 \%$, and $78 \%$ of the total species as contagiously distributed in the managed block I, II, and the control block, respectively. The lower proportion of contagiously distributed species in the managed block II might be the result of species having either lower abundance or lower frequency, as four species were recorded for only once in all the five plots sampled in managed block II. 
The SciFM has a negative effect on the plant diversity, shown by the lower value of Shannon-Weiner's index in the managed blocks in contrast to the control block. Similarly, results were further drawn by a significant positive correlation between the diversity index and canopy cover. Sapkota et al. (2010) found a decline in the tree diversity while increment in the dominance of $S$. robusta linearly along the disturbance gradient in the Nepalese Sal forest, similar to our study (Table 1). Mohammadi et al. (2008) and Awasthi et al. (2015) also found a decrease in the species diversity where Shelterwood Silvicultural System was practiced in the natural forest stands, similar to the results obtained. The species composition and diversity are related to the intensity of logging and type of management practices (de Avila et al. 2015), which means the higher the harvesting intensity the lower the species diversity in SciFM practices (Shima et al. 2018; Awasthi et al. 2020). Halpern and Spies (1995) also found other management activities (fertilization, herbicide application, grazing) could affect the species composition of vegetation in addition to the initial effect of logging and site preparation. However, a study by CarreñoRocabado et al. (2012) stated that disturbance intensity has almost no role in altering species richness or even the predicted species richness, which might be the effect of lower logging intensity.

The seedlings density of S. robusta was found higher in both the managed blocks in contrast to the control block. As per the definition of the status of regeneration (good, satisfactory, poor), the seedlings density was good in the managed blocks while just satisfactory in the control block (MFSC 2004), but the saplings density seemed poor in managed block I and control block while satisfactory in managed block II. The lower density of saplings in the managed block I might be the poor initial condition or advance growth in the block before regeneration felling with respect to the managed block II. The seedling density of S. robusta was higher after regeneration felling, while a similar result was obtained by Rautiainen and Suoheimo (1997). Similarly, higher seedling and sapling density of S. robusta was observed by Khanal and Adhikari (2018) in the scientifically managed forest in the Rupandehi district of Nepal, where Sal regeneration obtained higher light intensity under canopy opening for their growth. This result has been further confirmed by the significant negative correlation between canopy cover with seedlings density of Sal; similarly depicted by the lower density of seedlings in case of control or natural stands where the canopy was dense with lower overhead light for the under storey vegetation. This showed good regeneration in the managed area (block I and II) either in terms of seedlings or saplings density in comparison to the unmanaged area (control block) that predicts good future generation and productivity of the forest.

The estimated value of current annual increment (CAI) of forest in Nepal is 0.6 to 1.2 cubic meter per hectare, which is far below the potential productivity ( 8.60 cubic meters per hectare) of the site as determined by Paterson (1956) method, showing the potential to be increased 5-6 times if forests are managed scientifically (FAO 2009). The calculated potential productivity (CVP index, 1112.3) of the site lies within the CVP index class developed for moist and dry Sal (500-2000) by Champion et al 
(1965). A study report of NFA (2012) projected the timber and fuelwood demand for the Terai region would be 1.46 million cubic meters and 5.3 million tons respectively in 2020, and supply is far less than demand projected as indicated by ever-increasing timber price. Moreover, about $86 \%$ of households within the Kailali district consumed firewood as fuel followed by Liquid Petroleum Gas (7\%), showing high dependency upon the forest for fuel also (DDC 2015). Though Nepal has an area of $44.74 \%$ covered by forests and a large number of trees and timber (nearly 37.6 million cubic feet) die and decay in the forest, over $80 \%$ of timber (nearly 29.3 million cubic feet) was found imported from the foreign countries like Malaysia, Indonesia, Burma and so on in 2015, according to Federation of Forest-Based Industry and Trade, Nepal (The Himalayan Times 2016; Baral and Vacik 2018).

Effectiveness of any forest management practices relies on complexities or adoption and the cost or profit made (Poudyal et al. 2019). However, this study acknowledged some of the limitations as (1) cost regarding managing the matured natural forest might be underestimating and less in concluding the profitability studies as associated indirect cost and cost of raising the matured forest is missing (2) associated indirect benefits (monetary value) in managing the forest (natural regeneration/health of forest) were not computed (3) potential productivities based on climatic data were not compared with periodic measurement of similar types of managed forest. Meanwhile, passive forest management based on selective felling of the dead, dying, and diseased trees may promote the timber smugglings and degradation of the forest as demands of local people are not being entertained by the government (Subedi 2011). Also, the economic analysis such as the Benefit/Cost ratio and the Internal Rate of Returns almost ensured the positive impacts from the SciFM. The benefit-cost ratio of three of the collaborative forests (Tilaurakot, Gautam Buddha, and Banganga) was 4:1, 3:1, and 3.5:1 (Subedi 2011). This indicates the profitability and need for managing the natural forest scientifically rather than letting them decay and degrade as in the contemporary protection management regime.

\section{Conclusion and Recommendations}

This study was conducted to analyze the effects of SciFM on the regeneration of Sal (S. robusta), plant species diversity, and income through the flow of forest products in the community forest. The seedling density of $S$. robusta in the managed area was found to be higher than that in the unmanaged area of forest, which was also observed by the higher correlation of seedling density with canopy opening at their earlier stage of management practices. Plant diversity in unmanaged areas was found to be higher than in the managed area of forest affecting the species richness and evenness. The density of seedlings of $S$. robusta was low in the unmanaged area of forest, though the area has been fenced, which shows the need of opening the canopy for the promotion of regeneration in the study area. Paterson's CVP Index of the site was higher and its potential productivity was maximum. The productivity of the forest was found to be highest in both volumes of forest products and income in 
the last two years. Thus, SciFM promotes regeneration to reduce forest degradation, fulfill timber and fuelwood demand, and generate potential income for the community. SciFM, hence could be useful for the overall betterment of the remaining forest and associated communities in line with the slogan of "Forestry for Prosperity". Future research should explore the long term impacts of SciFM on plant species diversity. The market demand should be responded with appropriate management of forest and ensured a steady supply of forest products. In addition, there is also the need for developing large data sets on the permanent plots for understanding the long-term dynamics of regeneration, growth, wood production, and hence profitability from managing the community forest based on the silvicultural grounds.

\section{Literature Cited}

Awasthi, N., S. K. Bhandari, and Y. Khanal. 2015. Does Scientific Forest Management Promote Plant Species Diversity and Regeneration in Sal (Shorea Robusta) Forest? A Case Study from Lumbini Collaborative Forest, Rupandehi, Nepal. BankoJanakari 25 (1): 20-29. https://doi.org/10.3126/banko.v25i1.13468.

Awasthi, N., K. Aryal, B. B. K. Chhetri, S. K. Bhandari, Y. Khanal, P. Gotame, and K. Baral. 2020. Reflecting on Species Diversity and Regeneration Dynamics of Scientific Forest Management Practices in Nepal. Forest Ecology and Management 474 (June): 118378.

https://doi.org/10.1016/j.foreco.2020.118378.

Banjade, M. R., H. Dhungana, H. S. Luintel, R. Karki, and A. Gyanwali. 2012.

Discourse and Discursive Practices over Timber in Nepal Design and Layout

Discourse and Discursive Practices over Timber in Nepal. Journal of Forest and Livelihood 10 (1).

http:// citeseerx.ist.psu.edu/viewdoc/download?doi=10.1.1.942.5276\&rep=r ep1\&type $=$ pdf.

Baral, S., and H. Vacik. 2018. What Governs Tree Harvesting in Community ForestryRegulatory Instruments or Forest Bureaucrats' Discretion? Forests 10 (9).

Basyal, S., H. D. Lekhak, and A. Devkota. 2011. Regeneration of Shorea Robusta. Gaertn in Tropical Forest of Palpa District, Central Nepal. Scientific World 9 (9): 53-56. https://doi.org/10.3126/sw.v9i9.5519.

Carreño-Rocabado, G., M. Peña-Claros, F. Bongers, A. Alarcón, J. C. Licona, and L. Poorter. 2012. Effects of Disturbance Intensity on Species and Functional Diversity in a Tropical Forest. Journal of Ecology 100 (6): 1453-63. https://doi.org/10.1111/j.1365-2745.2012.02015.x.

Champion, H.G., S.K. Seth, and G.M. Khattak. 1965. Manual of Silviculture of Pakistan. Government Press, Pakistan.

Chauhan, P. S., J. D. S. Negi, L. Singh, and R .K. Monhas. 2008. Regeneration Status of Sal Forests of Doon Valley. Annals of Forestry 16 (2): 1781-82. 
DDC. 2015. Periodic District Development Plan, District Development Committee, Kailali, no. March: 77.

de Avila, A. L., A. R. Ruschel, J. O. P. de Carvalho, L. Mazzei, J. N. M. Silva, J. do C. Lopes, M. M. Araujo, C. F. Dormann, and J. Bauhus. 2015. Medium-Term Dynamics of Tree Species Composition in Response to Silvicultural Intervention Intensities in a Tropical Rain Forest. Biological Conservation 191: 577-86. https://doi.org/10.1016/j.biocon.2015.08.004.

DFRS. 2015. STATE of NEPAL'S FORESTS. Kathmandu, Nepal: Department of Forest Research and Survey. https://doi.org/978-9937-8896-3-6.

DHM. 2017. Observed Climate Trend Analysis of Nepal (1971-2014).Department of Hydrology and Meteorology, Kathmandu, Nepal.

DoF. 2014. Scientific Forest Management Guidelines. Kathmandu, Nepal: Government of Nepal, Ministry of Forests and Soil Conservation.

FAO. 2009. Nepal Forestry Outlook Study. Food and Agriculture Organization of the United Nations.

FAO. 2016. Sustainable Forest Management. Food and Agriculture Organization of the United Nations.

FRA/DFRS. 2015. Forest Resource Assessment Nepal Project/Department of Forest Research and Survey. Babarmahal, Kathmandu.

Halpern, C. B., and T. A. Spies. 1995. Plant Species Diversity in Natural and Managed Forests of the Pacific Northwest. Ecological Applications 5 (4): 91334. https://doi.org/10.2307/2269343.

Khanal, Y., and S. Adhikari. 2018. Regeneration Promotion and Income Generation through Scientific Forest Management in Community Forestry: A Case Study from Rupandehi District, Nepal. BankoJanakari 4: 45-53. https://doi.org/10.3126/banko.v27i3.20541.

Lutze, M., P. Ades, and R. Campbell. 2004. Review of Measures of Site Occupancy by Regeneration. Australian Forestry 67 (3): 164-71. https://doi.org/10.1080/00049158.2004.10674930.

MFSC. 2004. Community Forest Inventory Guideline. Kathmandu: Ministry of Forest and Soil Conservation.

MFSC. 2016. Forestry Sector Strategy (2016-25). Kathmandu, Nepal: Government of Nepal, Ministry of Forests and Soil Conservation.

Mishra, R. 1968. Ecology Workbook. Oxford \& IBH Publishing Company.

Mohammadi, J., S. Shataee, H. Habashi, and M. Amiri. 2008. Effect of Shelterwood Logging on Diversity of Tree Species in the Loveh Forest, Gorgan, October.

Mueller-Dombois, D., and H. Ellenberg. 1974. Aims and Methods of Vegetation Ecology. Wiley and Sons, New York. 
NFA. 2012. The Demand and Supply of Wood Products in Different Regions of Nepal Submitted to: REDD - Forestry Climate Change Cell Prepared by : Mijan Raj Regmi and Submitted by : Nepal Foresters' Association.

Odum, E. P. 1971. Fundamentals of Ecology. Third Edit. W.B. Saunders Co., Philadelphia.

Parkash, R., and S. L. Khanna. 1979. Theory and Practice of Silvicultural System. New Delhi, India: Periodical Expert Book Agency.

Paterson, S. S. 1956. The Forest Area of the World and Its Potential Productivity. Sweden: Goteburg University Press.

PCFMOP. 2017. Patela Community Forest Management Operational Plan. Dhangadhi, Kailali: PCFMOP.

Poudel, K. C. 2018. Silviculture for Forest Management in Nepal. BankoJanakari, no. 4: 15-20. https://doi.org/10.3126/banko.v27i3.20537.

Poudyal, B. H., T. Maraseni, and G. Cockfield. 2019. Scientific Forest Management Practice in Nepal: Critical Reflections from Stakeholders' Perspectives. Forests 11 (1). https:/ / doi.org/10.3390/f11010027.

Rautiainen, O., and J. Suoheimo. 1997. Natural Regeneration Potential and Early Development of Shorea Robusta Gaertn.f. Forest after Regeneration Felling in the Bhabar-Terai Zone in Nepal. Forest Ecology and Management 92 (1-3): 243-51. https://doi.org/10.1016/S0378-1127(96)03911-4.

Rutt, R. L., B. B. K. Chhetri, R. Pokharel, S. Rayamajhi, K. Tiwari, and T. Treue. 2015. The Scientific Framing of Forestry Decentralization in Nepal. Forest Policy and Economics 60: 50-61. https://doi.org/10.1016/j.forpol.2014.06.005.

Sapkota, I. P., M. Tigabu, and P. C. Odén. 2009. Spatial Distribution, Advanced Regeneration and Stand Structure of Nepalese Sal (Shorea Robusta) Forests Subject to Disturbances of Different Intensities. Forest Ecology and Management 257 (9): 1966-75. https://doi.org/10.1016/j.foreco.2009.02.008.

Sapkota, I. P., M. Tigabu, and P. C. Odén. 2010. Changes in Tree Species Diversity and Dominance across a Disturbance Gradient in Nepalese Sal (Shorea Robusta Gaertn. f.) Forests. Journal of Forestry Research 21 (1): 25-32. https://doi.org/10.1007/s11676-010-0004-4.

Shima, K., T. Yamada, T. Okuda, C. Fletcher, and A. R. Kassim. 2018. Dynamics of Tree Species Diversity in Unlogged and Selectively Logged Malaysian Forests. Scientific Reports 8 (1): 1-8. https://doi.org/10.1038/s41598-01819250-Z.

Singh, A. K., V. K. Kumar, and J. Singh. 1987. Forest Resource Economy and Environment. Concept Publishing Company, New Delhi, India.

Subedi, V. 2011. Forest Management Opportunities and Challenges in Nepal. The Nepal Journal of Forestry 14: 95-110. 
The Himalayan Times. 2016. "Over 80 per Cent of Timber Imported from Foreign Countries," June 19, 2016. https://thehimalayantimes.com/.

Tyagi, J. V., K. Rakesh, S. L. Srivastava, and R. D. Singh. 2011. Effect of MicroEnvironmental factors on Natural Regeneration of Sal. Journal of Forestry Research 22 (4): 543-550.

Whitford, P. B. 1949. Distribution of Woodland Plants in Relation to Succession and Clonal Growth. Ecology 30 (2): 199-208. 